the liver was as follows: "The section of the liver was seen to be extensively diseased. The centres of the lobules were disorganised, no appearance of liver tissue remained, being replaced by cell débris and altered blood pigment; the periphery of the lobules showed hepatic structure, but the cells were in an advanced state of degeneration."

The anresthetic used in Cases 2 and 3 was ohloroform, and no difficulty was experienced in its administration.

Huddersfield.

\section{NOTES OF A CASE OF SPLENECTOMY FOR INJURY.}

By J. CRAWFORD RENTON, M.D. EDIN.,

SURGEON AND LECTURER ON CLINICAL SURGERY, WESTERN INFIRMARY, GLASGOW ; FORMERLY EXAMINER IN SURGERY IN THE

UNIVERSITIES OF EDINBURGH AND ABERDEEN.

With a Report on the Condition of the Blond by J. MILL RenToN, M.B., Ch.B. Glasg., Extra-Dispensary Surgeon, Western Infirmary, Glasgow.

THE patient, aged 14 years, was sent to me at the Western Infirmary by Dr. T. W. Love of Airdrie on Dec. 17th, 1907 with a history of having been knocked down and run over by
The red blood corpuscles and hæmoglobin fell to their minimum 11 days after operation, and since then have gradually risen to normal. There was a marked polymorphonuclear leucocytosis for some weeks after operation. The most striking feature, however, has been the gradual increase in the relative number of the lymphocytes, and apparently fully a year after operation they were still increasing. Whether this condition will remain permanently or whether it is only a temporary phenomenon remains to be seen. D'Este Emery, ${ }^{1}$ however, in his cases, has found that at the end of three years the lymphocytes still represent $43 \cdot 25$ per cent. of the white cells, so that, if not permanent, the condition is at any rate of considerable duration. With the exception of a few mast cells nothing else of any note was observed in the blood.

The above case is of considerable interest as illustrating the importance of removing the spleen, not trusting to packing or stitching, and also the large amount of blood which may be lost and yet complete recovery takes place. The collections of the sterile fluid, both in the abdomen and the chest, have not often been noted, but in THE LANCET ${ }^{2} \mathrm{Mr}$. Sinclair White of Sheffield records a case in which sterile fluid collected in the abdomen after an operation on the stomach. The patient has recovered without any glandular enlarge-

Blood Examination.

\begin{tabular}{|c|c|c|c|c|c|c|c|}
\hline \multicolumn{2}{|c|}{$\begin{array}{c}\text { Dec. } 26 t h, 1907 \\
\text { (7 days after splenectomy). }\end{array}$} & \multirow{2}{*}{ Dec. 30th, 1907.} & \multirow{2}{*}{$\frac{\text { Jan. 10th, } 1908 .}{45 \%}$} & \multirow{2}{*}{ Feb. 20th, 1908.} & \multirow{2}{*}{ May 15th, 1908.} & \multirow{2}{*}{$\frac{\text { Oct. } 27 \mathrm{th}, 1908 .}{90 \%}$} & \multirow{2}{*}{$\frac{\text { Jan. 13th, } 1909 .}{95 \%}$} \\
\hline $\mathrm{Hb}$ & $=55 \%$ & & & & & & \\
\hline R.B.C & $=3,500,000$ & $2,160,000$ & $2,800,000$ & $4,000,000$ & $5,000,000$ & $5,040,000$ & $5,600,000$ \\
\hline W.B.C & $=40,560$ & 28,000 & 27,000 & 10,920 & 10,500 & 10,000 & 9,360 \\
\hline Polymorphs & $=89.5 \%$ & $86.9 \%$ & $83 \cdot 3 \%$ & - & $49 \%$ & $48.6 \%$ & $38 \cdot 7 \%$ \\
\hline Lymphocytes & $=9.9 \%$ & $12 \cdot 3 \%$ & $15 \cdot 7 \%$ & - & $46 \%$ & $48.6 \%$ & $58 \cdot 3 \%$ \\
\hline ,, SI & $1=4 \%$ & $4.6 \%$ & $7.5 \%$ & - & - & $36.2 \%$ & $44 \cdot 3 \%$ \\
\hline , & $=5.9 \%$ & $7 \cdot 7 \%$ & $8.2 \%$ & - & 一 & $12 \cdot 4 \%$ & $14 \%$ \\
\hline Eosinophils & $=0.3 \%$ & $0.3 \%$ & - & - & $4.5 \%$ & $1.58 \%$ & $2 \cdot 4 \%$ \\
\hline Myelocytes & $=0$ & $0.1 \%$ & $0.1 \%$ & - & - & - & 一 \\
\hline Nucleated reds & $=0$ & $0.1 \%$ & $0.1 \%$ & - & - & - & - \\
\hline Mast cells & $=0$ & - & - & - & $0.7 \%$ & $0.7 \%$ & $0.4 \%$ \\
\hline
\end{tabular}

a van 24 hours previously. On examination the patient was found to be very anæmic, restless, pulse 130, with great pain and tenderness and rigidity over the left half of the abdomen. It was quite evident that some serious injury had taken place and that hæmorrhage was going on rapidly. The abdomen was opened in the middle line and was full of blood. On passing the hand in the spleen was found to be ruptured. A small transverse incision was made to the left, the pedicle secured, and the spleen removed. It was torn across at the hilum so that the hæmorrhage was considerable. After the blood was removed from the abdominal cavity the incisions were closed.

The patient progressed favourably until Dec. 23rd, when he complained of abdominal discomfort, and it was evident that a certain amount of fluid had collected; a couple of stitches were removed and one and a half pints of fluid were evacuated, which was found to be sterile. On the 25th he complained of pain in the right side of the chest, the respirations were rapid, there was dulness at the right base, and 22 ounces of sterile fluid were drawn off. He continued well until Jan. 18th, when the temperature went up, and on examination dulness was found immediately below the right scapula. Exploration showed pus, and the chest was opened, a considerable amount of purulent fluid being evacuated, a cultivation from which gave a growth of pneumococcus. He gradually improved and went home early in March.

The counts were made by means of a Thoma-Zeiss hæmacytometer, the hæmoglobin being estimated by Gowers's hæmoglobinometer and T. W. Tallqvist's hæmoglobin scale, which was found to give approximately the same results as Gowers's instrument. The films were stained with Jenner's stain, and about 1000 corpuscles were counted in each film. The division of lymphocytes into small and large is only very approximate, as many intermediate forms were present. The above table shows the principal changes in the blood. ment. The examinations of the blood, which have been carefully carried out at regular intervals for a year, are of special interest. Glasgow.

\section{AN UNUSUAL CASE OF GOITRE.}

\section{By H. NEVILLF CROWE, M.B., B.CH. BIRM.,} M.R.C.S. ENG., L.R.C.P. LOND.,

LATE HOUSE SURGEON TO THE GENERAL HOSPITAL, BIRMINGHAM,

I AM kindly permitted by Sir Thomas Chavasse to publish the notes of the following interesting case, and to these notes Sir Thomas Chavasse has appended remarks.

The patient, a married woman, aged 54 years, was sent to the General Hospital by Mr. P. A. Docherty of Burton-on-Trent on June 11th, 1908, suffering from cellulitis of the neck and dyspnoea due to a goitre of the size of a clenched fist. The patient stated that the goitre was first noticed when she was 17 years old, and was treated with iodine and other counterirritants until she was 32 , and then, acting on the advice of her medical attendant, she was admitted into the Ear and Throat Hospital, Golden-square, London, under the care of the late Sir Morell Mackenzie. She remained in hospital for four months. The goitre was tapped and four ounces of fluid were withdrawn, but a subsequent tapping a fortnight later was negative. After an interval of 14 days some tincture of iodine was injected into the substance of the growth. This produced much constitutional and local disturbance, and when a subsidence had taken place a seton which she describes as a "tube and key" seton, was introduced into the middle line of the neck, and remained in sitrs

1 The Lancet, June 22nd, 1907, p. 1696.

2 THE LA TCET, Jan. 23rd, 1909, p. 235. 
for five weeks. As this caused no diminution in the size of the swelling she was recommended to return home, as the case was deemed incurable. Since leaving the hospital, 22 years ago, the sinus made by the seton had been continually discharging, and she had been subject to what she describes as "shivering fits." These always came on in the morning, the patient feeling at first very cold and shivering, followed in about an hour by a profuse sweating stage with vomiting lasting a further hour and then by 48 hours of extreme prostration. She stated that she had had as many as two of these attacks in a fortnight, and they were worse just before her menstrual periods. She noted that the attacks always came on when the discharge from the goitre ceased and were followed and relieved by a discharge of blood and pus from the sinus.

On admiation there was a large swelling in the neck extending from the level of the upper border of the thyroid cartilage above to the top of the sternum below; it was very fixed and apparently adherent to the cervical tissues. In the middle line, about the centre of the swelling, there was a sinus, into which a probe passed for about two and a half inches and from which there was a constant purulent secretion. The skin around was red and codematous. There was no dyspncea when the patient was at rest in bed, but it became evident when she walked about. The various organs of the body were healthy. The patient was treated with hot boric fomentations, and as a soft fluctuating area formed just below the old sinus an incision was made and a few drachms of pus were evacuated.

Operation.-On June 25th the following operation was performed. A horseshoe-shaped incision was made through the skin, commencing at the anterior edge of the right sternomastoid muscie at the level of the hyoid bone, carried forward to the middle line and then downwards, terminating on the right clavicle two inches external to the sterno-clavicular articulation. The skin flap thus marked out was dissected back with difficulty owing to its being adherent to the goitre. The thyroid tissue was very vascular and was firmly adherent to the trachea throughout its course, and it was only separated with great difficulty by dissection. The pedicles containing the superior and inferior thyroid arteries were secured and ligatured with cat-gut before division. The trachea was found to be much flattened from before backwards. After removal of the infected skin around the sinuses the wound was closed with silkworm-gut sutures, a drainage-tube being inserted at the lower part and the wound packed with iodoform gauze very lightly. With the exception of two stitch abscesses, the wound healed by first intention, and on July 24th the patient was discharged. When last seen on Nov. 6th the wound was soundly healed, the patient seemed in excellent health, and she reported that she had had no shivering fits since the operation.

Examination of the tumour. - In the middle of the thyroid tissue there was a cyst of the size of a hen's egg with thickened walls and calcareous lining, the contents of the cyst being purulent.

Pathological report by Mr. FRANK BARNEs, Visiting Clinical Pathoiogist.-Macroscopically the whole gland is apparently composed, firstly, of a very much thickened capsule, varying in thickness from a tenth to a quarter of an inch; secondly, of the gland substance which is hollowed out into a cyst having two openings on the anterior surface, one at the lower pole and one about the middle. The gland substance itself is placed mainly on the posterior wall of the cyst and is hard in consistence and traversed by yellowish bands of calcareous substance and having small yellowish areas of a similar nature, but in places softer. Much fibrous tissue runs through the gland substance, rendering it almost cartilaginous in consistence. Microscopically the specimen is for the most part composed of a thick-walled cyst. The wall of the cyst is in places composed of the thickened capsule of the gland, but in the deeper portion glandular substance showing much fibrosis and considerable small-celled infiltration projects into the lumen of the cyst, while here and there calcareous degeneration has set in. A portion of the wall of the cyst shows well-marked tubercles, the giant cell system being particularly well marked.

Remarks by Sir THOMAs CHAVASSE. - The case presents several points of interest. In the first place the method of treating bronchoceles by using a seton does not appear to have been quite extinct 22 years ago. In this instance it induced a chronic septic condition, with acute exacerbations at frequent intervals, and it is somewhat remarkable that the patient's general health did not suffer more, but during the greater portion of the 22 years she admitted that existence had hardly been endurable. Examination after removal showed that at no time could the drainage of the contained cyst have been efficient, the opening in its lower part being made after admission to the hospital, and that nothing but complete extirpation could bring about a radical cure. Probably operative measures would have been sought for at a much earlier date, but several medical opinions were expressed that the thickness and the induration of the cervical tissues, the apparent hardness of the goitre, together with the age of the patient, were suggestive that a malignant neoplasm, involving the trachea, had to be dealt with, and that excision could not be safely accomplished. The operation was admittedly much more difficult than an ordinary thyroidectomy, mainly owing to the firm adhesions to the rings of the trachea which existed throughout. The microscopic report bears evidence that degenerative changes of a mixed type were taking place in the tumour, the precise clinical significance of which will only be evident in the future.

Birmingham.

\section{A MODIFIED PLAN FOR THE PREPARA- TION OF CHROMIC CATGUT.}

BY CHARLES H. CHRISTAL, L.R.C.P. \& S. IREL.,

ASSISTANT MEDICAI OFFICER, HAMMERSMITH INFIRMARY, LONDON, W.

So many different methods have appeared within the last few years for the efficient preparation of catgut as a surgical ligature, most of which for various reasons have been discarded, that I trust I may be excused for adding yet another to the already long list of methods.

The claims of catgut as a surgical ligature were ardently supported by Lord Lister, to whom in the main its presentday popularity is due. The fact that it is absorbable by the living animal tissues is another factor in its favour, for having fulfilled its duty it disappears; and so the danger of subsequent irritation and infection due to the presence of a non-absorbable ligature which acts as a foreign body is eliminated. But catgut itself as it appears on the market in the raw state is a somewhat dangerous material if due precautions are not taken to render it sterile. Even when it is rendered sterile it may in itself induce suppuration when buried in healthy tissues. Many methods have been employed for sterilising catgut, but each of them has some disadvantages. The fact that catgut is rendered steriie does not necessarily make it a perfectly safe material for ligature. It has been noticed that absolutely aseptic catgut, when introduced into a wound, has the power of exciting suppuration. According to Ewald, this is due to some unknown toxic substance.

It appears rational to incorporate with the catgut some substance which acts as an antiseptic in itself, but such substance, exercising its antiseptic action, must have no deleterious effect on living tissue. If, for example, a ligature is prepared with corrosive sublimate its introduction is followed by coagulation of the albumin, and finally, necrosis of the tissue, which forms an excellent pabulum for microorganisms, in the event of their being present. Though this local necrosis is only microscopic, it occurs, and as we never can be certain that organisms are not introduced into the wound during the course of an operation, the fact is obvious that its use should be discarded. The same applies to all the different antiseptics which are used in the preparation of catgut, such as formalin, carbolic acid, the different salts of mercury, \&c.

The above-mentioned remarks do not apply so much to such materials as silk, silkworm gut, linen thread, and celluloid hemp. These ligatures are easily rendered sterile by boilt ing, and their subsequent sterility depends on their being kept immersed in an antiseptic fluid. Once they are in situ, providing due aseptic precautions are taken, they give rise to no further trouble. Not so with catgut. Besides its property of exciting suppuration as mentioned above, during the process of absorption, it may, if not sterile, liberate pathogenic microbes. Too much stress cannot, therefore, be placed upon the desirability of using an antiseptic catgut, as has been especially urged by Professor C. Yelverton Pearson of Cork and the late Nicholas Senn of Chicago. 